\title{
Social Justice as the Moral Core of Family Medicine: A Perspective from the Keystone IV Conference
}

\author{
Steven A. Schroeder, MD
}

A recurring conference theme was the essential place of social justice within family medicine, especially the need to focus on denominator populations, exalt the personal and caring qualities of doctoring, and address social determinants of health. Many expressed solidarity with "community," but it is not always easy to define community in our large and diverse nation. Exhortations for health advocacy were frequently voiced, but putting these into meaningful action agendas is a challenge. There was general agreement that medicine is in flux and that the many expressions of "commodity-centered consumerism" have altered organization and financing. The increasing demands by "consumers", who want low cost, instant availability, and shared decision-making, and yet change doctors when health plans alter coverage also differentially impact high-volume, low-margin specialties such as family medicine. Additional challenges were the electronic health record and calibrating an appropriate work/life balance. Five action steps are recommended: 1) speak out on the important social and moral issues; 2) be the experts on personal care; 3) make common cause with potential allies; 4) help institutions perceive the value of generalism; and 5) help find ways to enrich generalist disciplines to increase the joy of medicine and decrease the threat of burn out. (J Am Board Fam Med 2016;29:S69-S71.)

Guest editors' note: This paper was prepared after the G. Gayle Stephens Keystone IV Conference by the conference rapporteur, a seasoned personal physician and policy expert. It provides a synthesis and interpretation of the conference's meaning and importance.

Keywords: Doctoring, Family Medicine, Family Physician, Health Care Delivery, Personal Physician, Population Health, Primary Care, Professionalism, Social Justice

It was a privilege to be a guest in the house of family medicine. The energy, passion, and devotion to aspirational principles was bracing. Before proceeding with summary comments, I acknowledge some personal debts to family medicine. It has served to anchor primary care during boom and

This article was externally peer reviewed.

Submitted 1 April 2016; revised 1 April 2016; accepted 11 April 2016.

From the Department of Medicine and the Smoking Cessation Leadership Center, University of California, San Francisco.

Funding: This work was supported by a grant from the Robert Wood Johnson Foundation.

Conflict of interest: none declared.

Corresponding author: Steven A. Schroeder, MD, Department of Medicine, University of California, San Francisco, 3333 California Street, Suite 430 San Francisco, CA 941431211 (E-mail: Steve.Schroeder@ucsf.edu). bust years, staying true to its origins in the face of the seduction of medical technologies and the pressures accompanying the increasingly corporate nature of medical practice. The genesis of the Division of General Internal Medicine at the University of California, San Francisco, in 1980 stemmed in part from the pressures family medicine exerted on a previously subspecialty-dominated department of medicine. The opportunity to form that division, and to use it to help infuse a greater generalist presence within the University of California, San Francisco, behemoth was one of the great adventures of my career. Later, when I worked at the Robert Wood Johnson Foundation to promote primary care disciplines, I frequently turned to leaders in family medicine for advice and for stewardship of our programs. Finally, my current work at the Smoking Cessation 
Leadership Center involves motivating clinician groups to improve how their members help smokers quit. It is with mixed feelings that I confess that the American Academy of Family Physicians is one of our highest-performing partners, far exceeding my own discipline of internal medicine.

\section{General Comments}

A recurring conference theme was the essential role for social justice, especially the need to focus on denominator populations, to exalt the personal and caring qualities of being a physician, and to address social determinants of health. Sometimes I felt in a time warp, carried back into the turbulent era of the 1960s that empowered social justice movements of civil rights, women's rights, and gay rights and that protested the Vietnam War. In hindsight, progress since that time has been mixed: Although many real improvements have occurred, the health, income, and educational gaps between the more and the less fortunate have widened, our relative health status in the world is in continuous decline, and our political discourse has become more mean spirited. The backlash from that progressive era should remind us that it is not sufficient merely to express values of social justice, because incorporation of those values can be hard.

Many at the conference expressed solidarity with the "community," but it is not always easy to define community in our huge and diverse nation. Many seek to speak on its behalf, often with conflicting voices and credentials. Exhortations for health advocacy were also heard, and indeed there have been a number of successful health advocacy movements in recent decades-notably tobacco control and opposition to drunk driving. Other powerful advocacy movements, however, have threatened public health, such as the antivaccine, antiabortion, and gun rights movements. In my experience, messages to change public opinion in health have more power when linked with specific illnesses (breast cancer, autism, HIV/AIDS) than do general appeals for social justice. And the generalist disciplines, by definition, do not "own" any organ-specific diseases. Trying to start a health movement without involving passionate women advocates is a special challenge that we have confronted in our work. Although more women die of lung cancer than of breast cancer, there is no social movement to combat smoking in women-no race for the cure or brown ribbon, for example. And there is no public spokesperson against smoking. In my view there are 2 reasons for this neglect: stigma and class. The stigma occurs because there is often a sense that smokers caused lung cancer by making an unwise decision. And social class pertains because today smoking is essentially concentrated among marginalized populations that have little public or political clout.

The discussions were not exclusively confined to social values, however, because the very real changes in how medicine is conducted today were too important to ignore. There was general agreement that medicine is in flux and that "commoditycentered consumerism" has many expressions: the consolidation of the provider and insurance markets, the growing corporatization of medicine, and the purchasing of high-technology practices (eg, cardiology and gastroenterology) by hospitals to preserve referral patterns and to benefit from fee schedules that differentially pay more for hospital-owned services. As a high-volume, low-margin specialty, family medicine is less directly touched by these changes, but it suffers along with other such disciplines because of its lower perceived return on investment.

"Consumers"-as patients are increasingly called-are another part of this evolution. They value easy access, as evidenced by the popularity of walk-in clinics in pharmacies and other convenience sites. They consult online sources and may be better informed on some medical issues than their physicians. Not surprisingly, they are sensitive to costs, often abandoning their primary care physician if she is not in this year's covered health insurance network. And if they have a long wait in the doctor's office, a dismissive and anonymous comment is likely to appear in Yelp. Add to this the almost universal unhappiness among high-volume specialties such as family medicine with electronic health records and their seemingly incessant demands, and you get a picture of hard-working generalists struggling to keep up but feeling they are falling behind and losing control. Regarding the status of primary care at academic medical centers, 2 opposing forces exist: the traditional specialty centrifugal impulse to become ever more specialized and the newer recognition that holding organizations accountable for cost-effective total care and outcomes requires orchestration by generalists. How this tension will evolve is unclear, but based on prior track records, academic generalists should not be optimistic. Finally, the generational changes in what physicians see as appropriate professional life balance loomed over the 
discussion and will profoundly influence the response to the public promise challenges.

\section{Public Promises to Make}

Although it may be gratuitous for a non-family physician to respond to this challenge, here is my attempt.

1. Regarding relationships: "I will work with you to maximize your health and well-being"; "I will try to get to know you and understand what you want from me."

2. Regarding place: Recognizing that this issue is in great flux, "I will try to meet your needs, including sites of care."

3. Regarding time: "I, or one of my team, will be available for you." This promise admittedly ducks the issue of sending patients to the emergency department and visiting them, either officially or collegially, in the hospital.

\section{Action Steps for Family Medicine}

Family medicine, as the only unambiguously primary care medical specialty, is a core component of health care delivery and key to improving population health. It also has great potential appeal for idealistic young people who choose to enter medicine as a profession. Here are my recommendations for public actions:

1. Speak out on the important social and moral issues. When politicians equate palliative care with death panels, or refuse at the state level to adopt the Medicaid expansion component of the Affordable Care Act, be a moral voice for doing the right thing. Other potential roles for advo- cacy are medical student indebtedness, the overuse of medical care, and the need to address social determinants of health.

2. Be the experts on personal care. With increasing focus on patient satisfaction and the growing recognition that optimal outcomes are more likely with better physician-patient relationships, all physicians will be pressured to improve their ability to provide personal care. Family medicine should lead the way in this regardnationally, in academic medical centers, and in large medical group systems. They should be the expert champions of "personomics."

3. Make common cause with potential allies. A partial list includes general internists, general pediatricians, psychiatrists and other behavioral health experts, and the high-volume/low-technology subspecialties such as geriatrics, endocrinology, rheumatology, and infectious diseases. The allies might vary depending on the issue addressed, but whether it involves reforming information technology, rationalizing the physician fee schedule, or influencing medical school curriculum, there is strength in numbers.

4. Help institutions perceive the value of generalists. Whether creating accountable care organizations, practicing denominator medicine, or revitalizing office practice, family physicians can be the local experts for population health and clinical practice improvement.

5. Help find ways to enrich the practice of family medicine and other generalist disciplines to increase the joy of medicine and decrease the threat of burn out. 